\begin{tabular}{|c|c|c|}
\hline$T$ & $\begin{array}{c}\text { European Association for the } \\
\text { Development of Renewable Energies, Environment } \\
\text { and Power Quality (EA4EPQ) }\end{array}$ & $\begin{array}{l}\text { International Conference on Renewable Energies and Power Quality } \\
\text { (ICREPQ'12) } \\
\text { Santiago de Compostela (Spain), 28th to 30th March, } 2012\end{array}$ \\
\hline
\end{tabular}

\title{
Performance Analysis of SOFC Systems Integrated with Steam Reforming of Different Renewable Fuels
}

\author{
D. Saebea ${ }^{1}$, A. Authayanun ${ }^{1}$, Y. Patcharavorachot ${ }^{2}$, W. Paengjuntuek ${ }^{3}$ and A. Arponwichanop ${ }^{1 *}$ \\ ${ }^{1}$ Department of chemical engineering, Faculty of Engineering, Chulalongkorn University, Bangkok, 10330 Thailand \\ e-mail: Dang.s@student.chula.ac.th, Suthida.a@student.chula.ac.th,*Amornchai.a@chula.ac.th \\ ${ }^{2}$ School of Chemical Engineering, Faculty of Engineering, King Mongkut's Institute of Technology Ladkrabang, \\ Bangkok 10520, Thailand \\ e-mail: kpyaneep@kmitl.ac.th \\ ${ }^{3}$ Department of Chemical Engineering, Faculty of Engineering, Thammasat University, Patumthani 12120, Thailand \\ e-mail: pworanee@engr.tu.ac.th
}

\begin{abstract}
This study presents the performance analysis of a solid oxide fuel cell (SOFC) system integrated an external steam reforming process. Various renewable fuels such as ethanol, glycerol and biogas, are considered. Effect of key operating parameters of a steam reformer on hydrogen production for SOFC is investigated. The performance of the SOFC systems fed by different fuels in terms of electrical and termal efficiencies is compared. The results show that the biogas-fuelled SOFC system required the highest energy supply. The SOFC fed by ethanol can achieve the highest electrical and thermal efficiencies.
\end{abstract}

\section{Key words}

Solid Oxide Fuel Cell System, Steam Reforming, Renewable Fuels, Hydrogen Production

\section{Introduction}

Fuel cells can generate electricity via an electrochemical reaction by using hydrogen as fuel and oxygen as oxidant, so that hydrogen production technology has been developed together with fuel cell technology. In general, hydrogen is produced by reforming of methane derived from natural gas, which mostly comes from fossil resources. As fossil fuel is limited and causes environmental problems, the use of renewable fuel sources with environmental friendliness to produce hydrogen should be explored. Among the renewable fuels, ethanol, biogas and glycerol have been received considerable attention. Ethanol and biogas are derived from similar raw materials such as biomass, organic fraction of municipal solid waste or forestry residue materials but their production processes are different. Ethanol is produced through fermentation process, whereas biogas is generated by an anaerobic digestion process. Glycerol becomes an important fuel since it is a major by-product from the production of biodiesel, which its demand continuously increases. Regarding energy demand and environmental problems, these renewable are considered a promising alternative fuels for hydrogen production.

Among the various types of fuel cell, the solid oxide fuel cell (SOFC) is the most promising fuel cell technology, which can be used in a wide range of commercial applications. The high temperature operation of SOFC leads to many advantages. For example, the hightemperature waste heat from SOFC can be recovered for use in other heat-requiring units of SOFC systems. In addition, it is flexible to use various fuel types (i.e., methane, methanol and ethanol) [1]. Using a high-cost catalyst can be avoided as the electrochemical reaction is more pronounced at high temperatures [2].

There are a number of studies concerning about hydrogen production from renewable and the use of renewable fuels for SOFC system. In general, the most widely-used fuel processors for hydrogen production are steaming reforming, partial oxidation and auto-thermal processes. However, the steam reforming process provides a higher hydrogen yield and is suitable for hydrogen production from hydrocarbon fuels [3]. Toonssen et al. [4] investigated the SOFC/GT hybrid system integrated with a biomass gasification and showed that the gasification technology has slightly effect on the overall SOFC system performance. Farhad et al. [5] studied a SOFC microcombined heat and power system using biogas as a fuel. The heat generated from an afterburner was used to other heat-requiring units in the system, acheiving the highest thermal efficiency and electrical efficiency of the system. 
However, the thermal and electrical efficiency of the SOFC system depend on type of fuels used. As the thermal management and performance of SOFC systems using different fuels is discrepant, a detailed analysis of the SOFC system should be considered so as to select the suitable fuel for different applications of the SOFC system.

The aim of this study is to analyze a SOFC system integrated with a steam reforming process. Various renewable resouces such as biogas, etanol and glicerol, are cosidered for hydrogen production. Effects of operating condition on reformer performance are investigated. Finally, the performance of the SOFC integrated system for power generation is investigated.

\section{Description of SOFC System}

Fig. 1 shows an external reformer and SOFC integrated system, which composes of evaporator, heat exchanger, fuel processor, SOFC and afterburner. The steam and fuel are mixed and then vaporized in the evaporator. They are preheated at operating reforming temperatures and sent to the steam reformer where a synthesis gas (hydrogen-rich gas) is produced. The synthesis gas preheated at the desired temperature is fed to the SOFC. At the same time, air is compressed and preheated before entering the SOFC. SOFC produces electrical power and steam via an electrochemical reaction of hydrogen and oxygen in air. In general, SOFC cannot be operated at $100 \%$ fuel utilization, so that a residue fuel is combusted in an afterburner and then the heat generated from the afterburner is used for other heat-requiring units in the SOFC system such as preheators.

In this study, various renewable fuels such as biogas, ethanol and glycerol, are considered potential fuels to produce hydrogen for SOFC systems. Biogas is composed of $60 \mathrm{~mol} \%$ methane and $40 \mathrm{~mol} \%$ carbondioxide. To analyze the performance of the SOFC system, it was assumed that the system is run at steady-state condition and all gases behave as ideal-gases. Furthermore, heat losses from individual component in the SOFC system are negligible and the operating pressure and temperature of the reformer and the SOFC are kept constant. A planar SOFC is considered and a one-dimensional model is used to describe the SOFC, which is operated at a constant cell voltage along the cell coordinate.

\section{A. Fuel Processor}

Hydrocarbon fuels are reformed to produce a synthesis gas via a steam reforming reaction. The final composition of the synthesis gas at the equilibrium condition is determined from the minimization of Gibbs free energy. The main products of each fuel processing system are hydrogen, methane, carbon dioxide, carbon monoxide and water. Their equilibrium composition depends on the operating temperature and pressure of the steam reformer. Eq. (1) give the total Gibbs free energy of the system:

$$
G=\sum n_{i} G_{i}^{0}+\mathrm{RT} \sum n_{i} \ln \frac{y_{i} \varphi_{i} \mathrm{P}}{\mathrm{P}^{0}}
$$

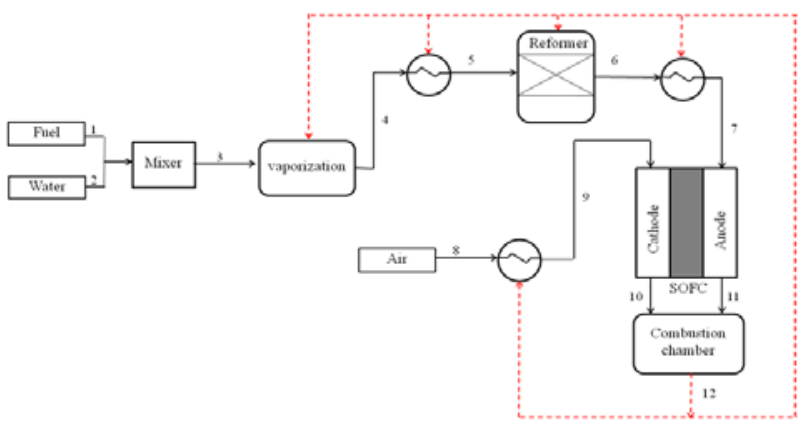

Fig. 1. Schematic of a SOFC system integrated with fuel processor.

where $G$ is the total Gibbs free energy, $n_{i}$ is the mole of species $i, G_{i}^{0}$ is the standard Gibbs free energy of species $i$, $R$ is the gas constant, $T$ is the reforming temperature, $P$ is the operating pressure of the reformer, $y_{i}$ is the mole fraction of species $i$ and $\varphi_{i}$ is the fugacity coefficient of a gas mixture obtained by Redlich-Kwong equation of state. The equilibrium compositions obtained from solving the minimization of Gibbs free energy have to satisfy the following constraints:

$$
\sum_{i=1}^{N} a_{j i} n_{i}=A_{j} \quad j=1, \ldots, k
$$

where $a_{j i}$ is the number of atoms of the $j$ element in the species $i$ and $A_{j}$ is the total atoms of the $j$ element in the feed stream.

The heat required for operation of the steam reformer at isothermal condition can be computed from energy balance equation given as:

$$
Q_{\mathrm{SR}}=\left(\sum_{i} \dot{n}_{\mathrm{i}, \mathrm{r}}^{\text {out }} \dot{h}_{\mathrm{i}, \mathrm{r}}^{\text {out }}\right)-\left(\sum_{i} \dot{n}_{\mathrm{i}, \mathrm{r}}^{\dot{\mathrm{i}}_{\mathrm{i}, \mathrm{r}}} \dot{h}^{\text {in }}\right)
$$

where $\dot{n}_{\mathrm{i}, \mathrm{r}}$ is the molar flow rate of species $i$ and $\dot{h}_{\mathrm{i}, \mathrm{r}}$ is the enthalpy of species $i$.

\section{B. SOFC Model}

The reforming gas consisting of $\mathrm{CH}_{4}, \mathrm{H}_{2} \mathrm{O}, \mathrm{CO}, \mathrm{H}_{2}$, and $\mathrm{CO}_{2}$ are fed into the fuel cannel of SOFC, whereas air consisting of $\mathrm{O}_{2}$ and $\mathrm{N}_{2}$ is fed into the air channel. In general, hydrocarbon fuels can be further converted to hydrogen and carbon dioxide by steam reforming and water gas shift reactions (Eqs. (4), (5)) in the SOFC because it is operated at high temperaturas and the anode catalyst can be accelerate these reactions.

$$
\begin{aligned}
& \mathrm{CH}_{4}+\mathrm{H}_{2} \mathrm{O} \leftrightarrow 3 \mathrm{H}_{2}+\mathrm{CO} \\
& \mathrm{CO}+\mathrm{H}_{2} \mathrm{O} \leftrightarrow \mathrm{H}_{2}+\mathrm{CO}_{2}
\end{aligned}
$$

In SOFC operation, hydrogen is consumed in the electrochemical reaction to produce the electricity, whereas oxygen in air is reduced into oxygen ion at the cathode side. The electrochemical reactions taking place at the fuel and air channels of SOFC are given in Eqs. (6)(8).

Hydrogen oxidation reaction:

$$
\mathrm{H}_{2}+\mathrm{O}^{2-} \leftrightarrow \mathrm{H}_{2} \mathrm{O}+2 \mathrm{e}^{-}
$$

Oxygen reduction reaction:

$$
1 / 2 \mathrm{O}_{2}+2 \mathrm{e}^{-} \leftrightarrow \mathrm{O}^{2-}
$$


Overall cell reaction:

$$
\mathrm{H}_{2}+1 / 2 \mathrm{O}_{2} \leftrightarrow \mathrm{H}_{2} \mathrm{O}
$$

The component concentrations in fuel and air channels along the flow direction can be described the following equations:

Fuel channel: $\left(i=\mathrm{CH}_{4}, \mathrm{H}_{2} \mathrm{O}, \mathrm{CO}, \mathrm{H}_{2}\right.$, and $\left.\mathrm{CO}_{2}\right)$

$$
\frac{d C_{\mathrm{i}, \mathrm{f}}}{d x}=\frac{1}{u_{\mathrm{f}}} \sum_{\mathrm{k} \in\{(\mathrm{i}),(\mathrm{ii}),(\mathrm{v})\}} v_{\mathrm{i}, \mathrm{k}} R_{\mathrm{k}} \frac{1}{h_{\mathrm{f}}}
$$

Air channel: $\left(i=\mathrm{O}_{2}\right.$ and $\left.\mathrm{N}_{2}\right)$

$$
\frac{d C_{\mathrm{i}, \mathrm{a}}}{d x}=\frac{1}{u_{\mathrm{a}}} v_{\mathrm{i},(\mathrm{v})} R_{(\mathrm{v})} \frac{1}{h_{\mathrm{a}}}
$$

The theoretical open-circuit potential can be expressed by the Nernst equation:

$$
E^{\mathrm{OCV}}=E^{0}-\frac{R T}{2 F} \ln \left(\frac{P_{\mathrm{H}_{2} \mathrm{O}}}{P_{\mathrm{H}_{2}} P_{\mathrm{O}_{2}}^{0.5}}\right)
$$

where $E^{0}$ is the open-circuit voltage at the standard pressure and is a function of the operating temperature.

Due to internal voltage losses, the actual voltage $(V)$ decreases from its open-circuit voltage (Eq. (12)).

$$
V=E-\eta_{\text {ohmic }}-\eta_{\text {conc }}-\eta_{\text {act }}
$$

where $\eta_{\text {ohmic }}, \eta_{\text {conc }}, \eta_{\text {act }}$ are the ohmic, concentration, activation losses, respectively.

The ohmic losses can be explained by a linear relation of voltage drop and current density as:

$$
\eta_{\text {ohm }}=j R_{\text {ohm }}
$$

where $R_{\mathrm{ohm}}$ is the internal electrical resistance depending on the conductivity and thickness of individual fuel cell layers.

The concentration overpotentials is due to the insufficiency of hydrogen at the reaction sites as described by Eq. (14):

$$
\eta_{\text {conc }}=\left(\frac{R T}{2 F} \ln \left(\frac{p_{\mathrm{H}_{2} \mathrm{O}, \mathrm{TPB}} p_{\mathrm{H}_{2} \mathrm{f}}}{p_{\mathrm{H}_{2} \mathrm{O}, \mathrm{f}} p_{\mathrm{H}_{2}, \mathrm{TPB}}}\right)\right)_{\text {anode }}+\left(\frac{R T}{4 F} \ln \left(\frac{p_{\mathrm{O}_{2}, \mathrm{a}}}{p_{\mathrm{O}_{2}, \mathrm{TPB}}}\right)\right)_{\text {cathode }}
$$

The partial pressures of $\mathrm{H}_{2}, \mathrm{H}_{2} \mathrm{O}$ and $\mathrm{O}_{2}$ at the three-phase boundaries can be determined by using a gas transport model in porous media.

The activation overpotentials can determined from the non-linear Butler-Volmer equation, which relates the current density to the activation overpotential as:

$$
\begin{gathered}
j=j_{0, \text { anode }}\left[\frac{p_{\mathrm{H}_{2}, \mathrm{TPB}}}{p_{\mathrm{H}_{2,5}}} \exp \left(\frac{\alpha n F}{R T} \eta_{\text {act,anode }}\right)-\frac{p_{\mathrm{H}_{2} \mathrm{O}, \mathrm{TPB}}}{p_{\mathrm{H}_{2} \mathrm{O}, \mathrm{f}}} \exp \left(-\frac{(1-\alpha) n F}{R T} \eta_{\text {act,anode }}\right)\right] \\
j=j_{0, \text { cathode }}\left[\exp \left(\frac{\alpha n F}{R T} \eta_{\text {act, athode }}\right)-\exp \left(-\frac{(1-\alpha) n F}{R T} \eta_{\text {act, cathode }}\right)\right]
\end{gathered}
$$

where $\alpha$ is the transfer coefficient $(=0.5), n$ is the number of electrons transferred in the single elementary ratelimiting reaction step, $i_{0 \text {,cathode }}$ and $i_{0 \text {,anode }}$ is the exchange current density at the anode and cathode, respectively.

To evaluate the performance of SOFC, the overall fuel utilization $\left(U_{\mathrm{f}}\right)$ and the electrical power output $\left(P_{\text {sofc }}\right)$ are determined as:

$$
\begin{gathered}
U_{\mathrm{f}}=\frac{j_{\text {avg }} L W}{2 F\left(4 \dot{n}_{\mathrm{CH}_{4}}^{\text {in }}+\dot{n}_{\mathrm{H}_{2}}^{\text {in }}+\dot{n}_{\mathrm{co}}^{\text {in }}\right)} \\
P_{\text {sofc, Dc }}=j_{\text {avg }} \times V_{\text {actual }} \times A_{\mathrm{c}}
\end{gathered}
$$

where $j_{\text {avg }}$ is the average current density, $\dot{n}^{\text {in }}$ is the inlet molar flow rate of species $i$ and $A_{c}$ is the active area of fuel cell.

As the SOFC is assumed to be operated under adiabatic condition, excess air is fed into the SOFC in order to control the operating temperatura at a desired value. The difference of the inlet and outlet fuel cell temperature is limited to $100 \mathrm{~K}$. As a result, an amount of inlet air can be calculated from the energy balance around a fuel cell control volume as:

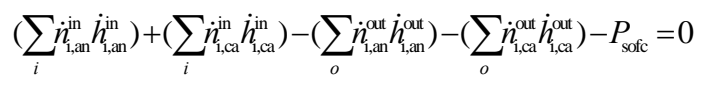

All the equations describing the SOFC system are coded and solved in Matlab. In this study, the SOFC system is designed for the net power output of $150 \mathrm{~kW}$ and the fuel utilization of 0.7 by varying the molar flow rate of fuel.

\section{Results and Discussion}

Fig. 2 shows effect of operating temperature on hydrogen production from the steam reforming of biogas, ethanol and glycerol. The results show a similar trend even different fuels are utilized. An increase in the temperatures enhance hydrogen yield due to the endothermicity of the steam reformign reaction.

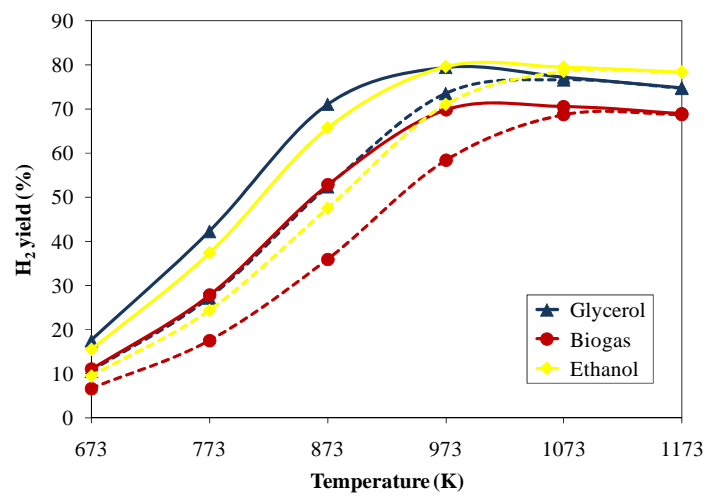

Fig. 2. Effect of reforming temperature on $\mathrm{H}_{2}$ yield (steam to carbon ratio $=2$ ): $P=1$ bar (solid line) and $P=3$ bar (dash line).

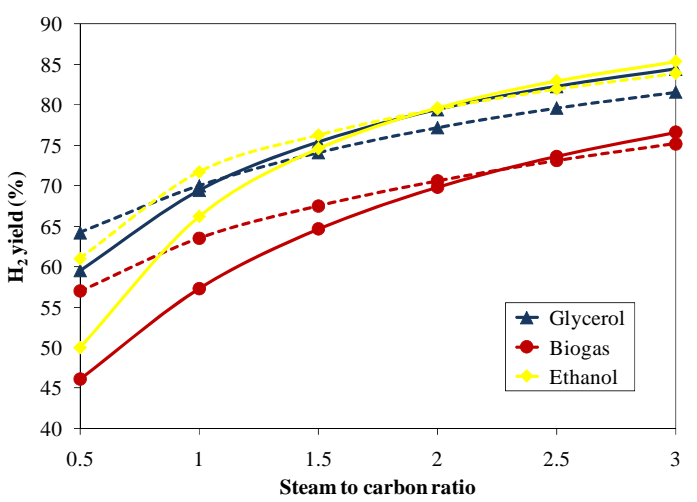

Fig. 3. Effect of steam to carbon ratio on $\mathrm{H}_{2}$ yield $(P=1$ bar): $T$ $=973 \mathrm{~K}$ (solid line) and $T=1073 \mathrm{~K}$ (dash line). 


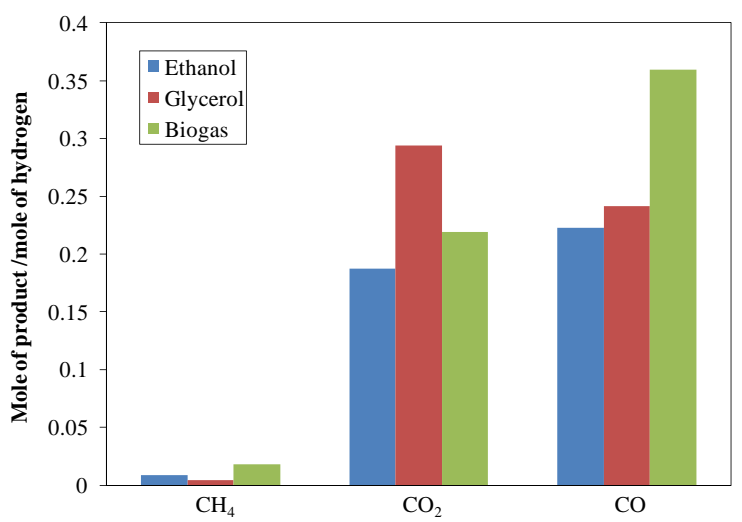

Fig. 4. Product distribution from steam reforming of glycerol, ethanol and biogas $(T=973 \mathrm{~K}$ and $\mathrm{S} / \mathrm{C}$ ration $=2)$.

It is found that ethanol and glycerol provide higher hydrogen yield, compared to biogas. At atmospheric pressure, glycerol provides higher hydrogen yield than ethanol at the temperature below $973 \mathrm{~K}$. When the reformer is operated at high pressure, the use of glycerol can produce more hydrogen than that of ethanol at the temperature below $1033 \mathrm{~K}$.

Fig. 3 shows the effect of steam to carbon (S/C) ratio on hydrogen yield at pressure of 1 bar. At low S/C ratio, glycerol provides higher hydrogen than ethanol. However, ethanol gives the highest hydrogen yield at a higher S/C ratio. The use of biogas provides the lowest yield of hydrogen at all operational range studied.

The compositions of synthesis gas obtained from the steam reforming of glycerol, ethanol and biogas at temperature of $973 \mathrm{~K}$ and S/C ratio of 2 are shown in Fig. 4. When ethanol are used as a fuel, $\mathrm{CO}$ is less produced. It is noted that the presence of $\mathrm{CO}$ causes the formation of carbon in SOFC. Additional purification would be required to reduce $\mathrm{CO}$ content. From the results, it is also observed that the glycerol reforming process gives the highest value of $\mathrm{CO}_{2}$ concentration. This is due to the fact that the molecular structure of glycerol has a hydrogen to carbon ratio lower than other fuels.

Next, the performance of SOFC fed by the synthesis gas obtained from the steam reforming of ethanol, glycerol and biogas is investigated. The power output of the SOFC system is specified at $150 \mathrm{~kW}$.

Fig. 5 shows a fraction of heat duty required for each unit in the SOFC system. It is indicated that the air preheater needs the highest energy, which is equal to $79-81 \%$ of the overall energy consumption in the SOFC system. Generally, SOFC is operated at high temperatures and the electrochemical reaction is an exothermic reaction. These causes the temperature gradient in the SOFC stack. Therefore, the excess air is required to maintian the operating temperature of the SOFC at a suitable level. The steam reformer is the other unit that requires much energy. (a)

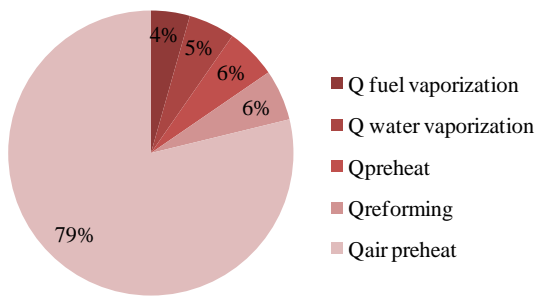

(b)

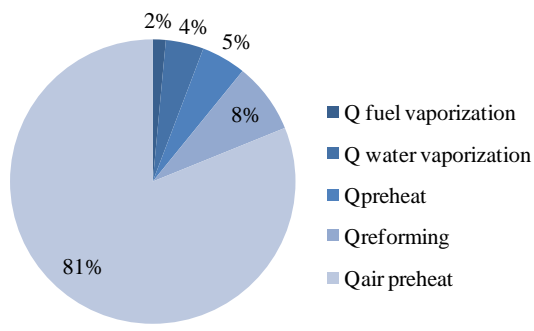

(c)

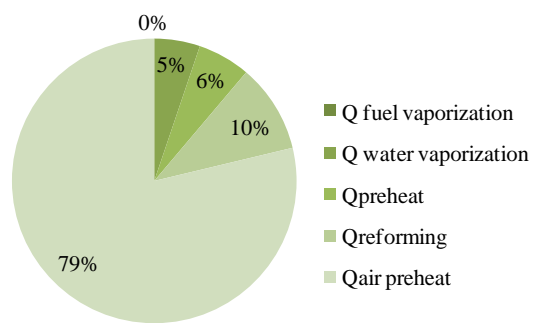

Fig. 5. Distribution of energy consumption in a SOFC system fed by different fuels: (a) Ethanol, (b) Glycerol and (c) Biogas.

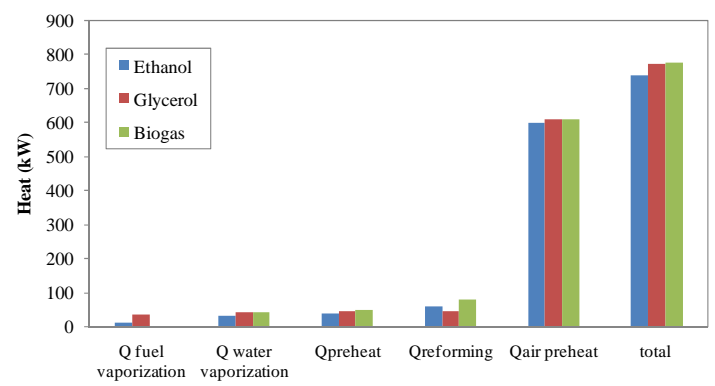

Fig. 6. Energy required in each unit of SOFC systems with different fuel feeds.

The energy consumptions in each unit of the SOFC system fed by different fuels are shown in Fig. 6. The results indicate that the SOFC system run on biogas requires the highest external energy supply, whereas the ethanol-fueled SOFC system shows the lowest requirement of energy. It is noticed the the reforming of biogas needs high energy supply $(77.9 \mathrm{~kW})$. A high content of $\mathrm{CO}_{2}$ in biogas increases a reverse water gas reaction, which is a endothermic reaction. Although the energy requirement of the glycerol steam reforming is lower, a higher heat is needed for the evaporator due to a high boiling point of glycerol (561.9 K). 


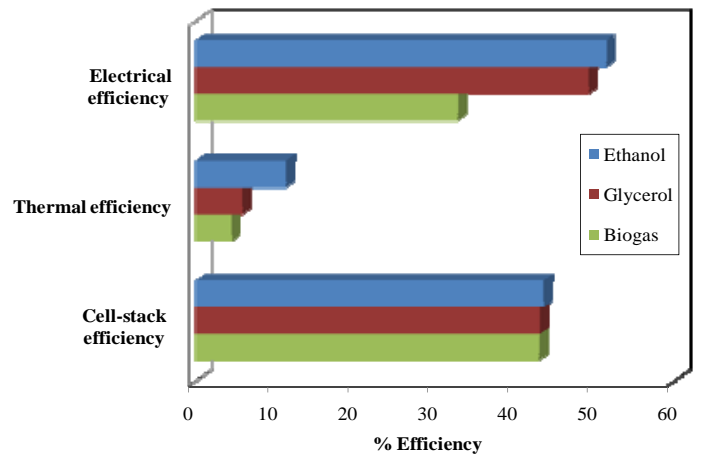

Fig. 7. Efficiencies of SOFC systems fuelled by different fuels.

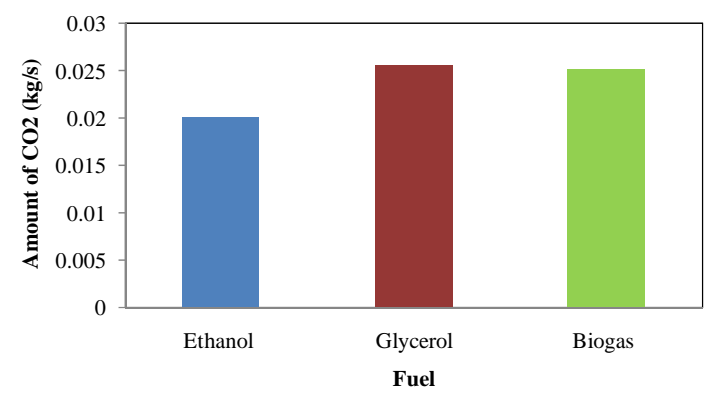

Fig. 8. $\mathrm{CO}_{2}$ released from SOFC systems fuelled by different fuels.

Fig. 7 shows the SOFC stack efficiency and the thermal efficiency and electrical efficiency of the SOFC system supplied by different fuels. As can be seen, the SOFC system fuelled by ethanol gives the best performance in terms of the SOFC stack efficiency, the electrical efficiency and the thermal efficiency. This results from a high performance of the ethanol steam reformer that gives the highest hydrogen production, compared to the reforming of other fuels. The ethanol fuelled SOFC system can acheive the electrical efficiency of $51 \%$, whereas that of the SOFC system supplied by glycerol and biogas is $49 \%$ and $32 \%$, respectively. The use of biogas as a fuel for the SOFC system provides the minimun electrical efficiency since biogas mainly consists of carbon dioxide that dilutes the hydrogen fuel fed to the SOFC stack. This lowers the reversible cell voltage and increases the concentration and activation overpotentials in the SOFC. It is noted that the efficiency of the SOFC stack run on different fuel feeds is indifferent (42-43\%). Considering the thermal efficiency, the results show that the SOFC system fed by biogas shows the lowest thermal efficiency since the desired power output of $150 \mathrm{~kW}$. In addition, a lot of heat is lost to preheat carbon dioxide in biogas feed.

Fig. 8 presents the amount of carbon dioxide released from the SOFC system at the power output of $150 \mathrm{~kW}$. The SOFC system fed by ethanol minimizes the emission of carbon dioxide, whereas the glycerol-fuelled SOFC system shows the maximum. The carbon dioxide emission of the ethanol-fed SOFC system is less than other system by $21.76 \%$ (glycerol) and $19.97 \%$ (biogas).

The simulation study indicates that ethanol is the most suitable fuel for the SOFC system integrated with an external steam reformer. It provides not only the miximum SOFC stack efficiency, system electrical efficiency and thermal efficiency, but also the minimum of carbon dioxide emission. It is suggested that if biogas is used as a fuel for SOFC, a purification unit to remove carbon oxide from biogas is necessary. Therefore, ethanol is considered an attractive renewable fuel for the SOFC system.

\section{Conclusions}

This study presented a performance analysis of a steam reforming process and solid oxide fuel cell (SOFC) integrated system. Various renewable fuels, i.e., glycerol, ethanol and biogas, were used to generate hydrogen for SOFC. The results showed that the SOFC system supplied by biogas requires the highest energy and give the lowest electrical and thermal efficiencies. The use of ethanol seems to be a promising fuel for the SOFC system as the highest electrical and thermal efficiencies can be acheived and in addition, the emission of carbon dioxide is less released.

\section{Acknowledgements}

Support from the Thailand Research Fund, the Special Task Force for Activating Research (STAR), Chulalongkorn University Centenary Academic Development Project, and the Higher Education Research Promotion and National Research University Project of Thailand, Office of the Higher Education Commission (EN280A) is also gratefully acknowledged

D. Saebea would like to thank the Office of the Higher Education Commission, Thailand for supporting by grant fund under the program "Strategic Scholarships for Frontier Research Network for the Join Ph.D. Program Thai Doctoral degree" for this research.

\section{References}

[1] W. H. Lai, C. A. Hsiao, C. H. Lee, Y. P. Chyou, Y. C. Tsai, Experimental simulation on the integration of solid oxide fuel cell and micro-turbine generation system, Journal of power sources 2007, 171, pp. 130-139.

[2] S. Cordiner, M. Feola, V. Mulone, F. Romanelli, Analysis of a SOFC energy generation system fuelled with biomass reformate. Applied Thermal Engineering 2007, 27, pp. 738747.

[3] G. Rabenstein, V. Hacker, Hydrogen for fuel cells from ethanol by steam-reforming, partial-oxidation and combined auto-thermal reforming: A thermodynamic analysis. Journal of Power Sources 2008, 185, pp. 1293-1304.

[4] R. Toonssen, S. Sollai, P.V. Aravind, N. Woudstra, A. H. M. Verkooijen, Alternative system designs of biomass gasification SOFC/GT hybrid system. International journal of hydrogen energy 2011, 36, pp. 10414-10425.

[5] S. Farhad, F. Hamdullahpur, Y. Yoo, Performance evaluation of different configurations of biogas-fuelled SOFC microCHP systems for residential applications, International journal of hydrogen energy 2010, 35, pp. 3758-3768. 